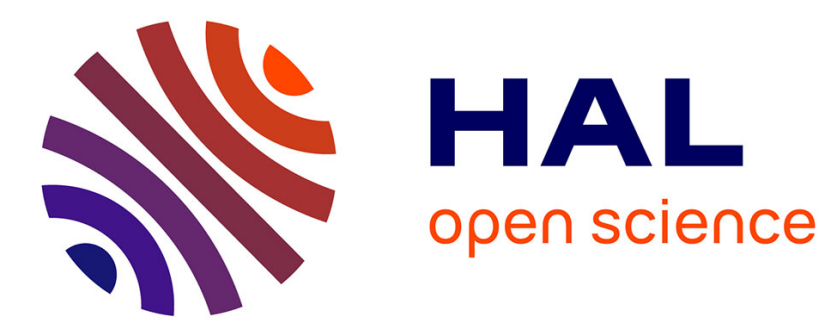

\title{
The Safety-net Use of Non Timber Forest Products Philippe Delacote
}

\section{To cite this version:}

Philippe Delacote. The Safety-net Use of Non Timber Forest Products. 30 p., 2008, Documents de

Travail. INRA Laboratoire d'Economie Forestière (LEF), 2008-04. hal-01189310

\section{HAL Id: hal-01189310 https://hal.science/hal-01189310}

Submitted on 6 Jun 2020

HAL is a multi-disciplinary open access archive for the deposit and dissemination of scientific research documents, whether they are published or not. The documents may come from teaching and research institutions in France or abroad, or from public or private research centers.
L'archive ouverte pluridisciplinaire HAL, est destinée au dépôt et à la diffusion de documents scientifiques de niveau recherche, publiés ou non, émanant des établissements d'enseignement et de recherche français ou étrangers, des laboratoires publics ou privés. 


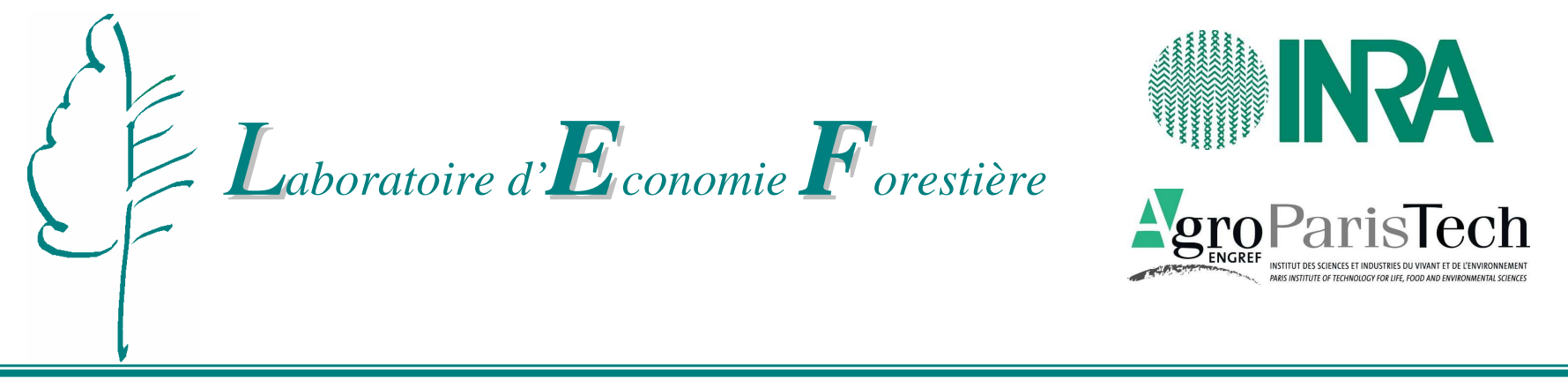

\section{The Safety-net Use of Non Timber Forest Products}

Philippe DELACOTE

Septembre 2008

Document de travail

$n^{\circ}$ 2008-04 


\title{
The Safety-net Use of Non Timber Forest Products
}

\author{
Philippe DELACOTE ${ }^{1,2}$
}

Septembre 2008

Document de travail du LEF $\mathrm{n}^{\circ} \mathbf{2 0 0 8 - 0 4}$

\author{
Résumé \\ Les produits forestiers en tant qu'outil de gestion du risque
}

L'incomplétude des marché d'assurance est une lacune récurrente dans les pays en développement. Dans ce contexte, les ménages pauvres des régions rurales exploitent souvent les propriétés en ressource commune en tant qu'outil de gestion du risque en cas de pénurie. Cet article étudie les implications de ce type d'utilisation sur le couvert forestier, et donc la déforestation, ainsi que sur l'intensité de l'utilisation des ressources. Le modèle de choix d'utilisation des terres est ainsi proche d'un modèle de portefeuille entre une activité risquée, l'agriculture, et un outil de gestion du risque, l'extraction de produits forestiers. D'autre part, il est démontré que cette stratégie d'assurance peut conduire à une trappe de pauvreté, par un mécanisme de tragédie des communs.

Mots clés : déforestation; modèle de ménage; aversion au risque; expansion agricole; produits forestiers.

\begin{abstract}
Incompleteness of insurance markets is a crucial weakness of developing countries. In this context, the poor households of rural regions often exploit common property resources, such as forests, as insurance in case of economics stress. The aim of this paper is to derive the implications of this insurance use on the forest cover, and thus on deforestation. The land-use choice between agricultural land and forest therefore resembles a portfolio diversification. However, I also show that this insurance strategy may lead to resource overexploitation and constitute a poverty trap.
\end{abstract}

Key words: deforestation, household model, risk aversion, agricultural expansion, forest products.

Classification JEL : O12, O13, Q12, Q15, Q23.

\footnotetext{
${ }^{1}$ INRA, UMR356 Economie Forestière, F-54000 Nancy, France Email Philippe.Delacote@ nancy-engref.inra.fr

${ }^{2}$ AgroParisTech, Engref, Laboratoire d'Economie Forestière, F-54000 Nancy, France
} 


\section{Introduction}

Insurance markets of rural regions in developing countries are often incomplete, if not nonexistent. This situation gives non-conventional insurance systems an important role. Among these systems, common property resources (CPR) appear to have an important insurance role. Several case studies have studied the insurance role of commonly held resources, such as forests, commonly held lands or even fisheries.

A particular activity is often used as a safety net ${ }^{1}$ : Non-Timber Forest Products (NTFP) extraction $^{2}$. Populations of interest here are farming communities that rely on forest as a supplementary source of income (Byron and Arnold, 1999). In case of bad agricultural crops, the households extract NTFP from the forest in order to smooth their consumption.

The aim of this paper is to understand the impact of this insurance use of forest products on the land-use choice. Indeed, agricultural expansion appears to be the most important cause of deforestation. The share of deforestation related to agricultural expansion has been estimated at at least 50 per cent (Myers, 1992; UNEP, 1992) and at 70 per cent in the 1990's (UNEP, 2003). In Africa, which is the area with the highest deforestation rates in the world, more than 50 per cent of the deforested zones were switched into small exploitations. Simultaneously, agricultural development is an important tool for poverty alleviation and long term development (World Bank; 2000). The consequences of this insurance role of NTFP extraction on deforestation is thus an interesting issue and can be investigated with farm household models - a priority for future research (Angelsen and Kaimowitz, 1998).

Some papers have studied the safety-net role of common property resources, such as forests (Agarwal, 1991 ; Baland and Francois, 2004 ; Pattanayak and Sills, 2001), but they do not consider the impact of this role on the land-use decision. However the households face a trade-off between forest and agriculture. Agriculture can be a way to alleviate poverty, but is a risky activity, while NTFP extraction has low poverty alleviation potential, but is a useful tool to compensate for agricultural risk. This paper investigates therefore the impact of the use of NTFP as safety nets on the household's decision to increase their agricultural land, and thus, to clear forests.

\footnotetext{
${ }^{1}$ Among other insurance mechanisms: inter-household solidarity, livestock...

${ }^{2}$ The term "non-timber forest product" encompasses all biological materials other than timber which are extracted from forests for human use.
} 
The safety-net use of NTFP extraction may take two forms, corresponding to two kinds of risk-management strategies. First, the diversification strategy is equivalent to a portfolio analysis, because the households use NTFP extraction as a risk-free asset (Aldermann and Paxson, 1994). Second, the coping strategy consists of extracting NTFP only when agricultural output is too low, working as a "natural" insurance mechanism. Therefore, the problem for the local communities has both the characteristics of portfolio analysis and economics of insurance. The paper focuses on the diversification strategy. The household chooses ex ante the share of land dedicated to agriculture and the share of land dedicated to NTFP extraction. The analysis of a coping strategy would induce a different timing of the land-use choice and the allocation of labor.

To investigate the impact of the use of NTFP as a risk-management strategy, we build on Angelsen (1999). Our extension allows for agricultural crops uncertainty and for NTFP extraction, neither of which is considered in Angelsen (1999). Thus the model is an expected utility maximization process of a risk-averse household which uses forest products to face agricultural crops uncertainty. We assume a community that does not have access to insurance nor credit market, so that the risk-management use of forest products is the only way to deal with crop risks.

In this context, the comparative statics show that risk reduction, lower risk aversion and larger population may be important factors of deforestation. Moreover, forest profitability is unambiguously positively correlated with the forest cover.

Angelsen and Wunder (2003) notes that this activity can constitute a poverty trap for poorer households. Azariadis and Stachuski (in Aghion and Durlauf, 2006) define a poverty trap as a "self reinforcing mechanism which causes poverty to persist". Thus determining the conditions under which a CPR constitutes both a safety net and a poverty trap is also an important issue. I define a poverty trap as a situation in which households cannot get more than their subsistence requirement from their activities. In the case considered here, households are "trapped" in CPR extraction activity because of their need of insurance, which keeps them away from other development opportunities. CPR extraction can constitute a poverty trap as a result of a tragedy-of-the-commons process. Too much households are in need of insurance and the resource cannot provide enough to properly insure all the 
population. They face thus the classic poverty-environment nexus, where poor people depend too much of their environment and overuse it.

Section 2 gives a brief review of the literature, emphasizing the use of NTFP for poor agricultural households, describing the economics of land-use in agricultural areas and the insurance properties of common property resources. Section 3 presents a household model of land-use choice with risk on agricultural output and NTFP extraction used as safety net. Section 4 shows how a CPR may constitute both a safety net and a poverty trap. Finally section 5 concludes and discusses the policy implications.

\section{Review of the literature}

\subsection{The safety-net use of non-timber forest products}

In developing countries, about 1.2 billion people rely on agroforestry farming systems that help to sustain agricultural productivity and generate income (World Bank, 2001). The risk-management role of forest products is particularly important in the rural regions of developing countries, given that agricultural crops face many types of risk, such as price shocks, seasonal flooding, unpredictable soil quality, pests, crop diseases or illnesses. NTFP can be used directly in consumption or sold to fill cash gaps. Formally, rural households, which have limited credit and insurance options, choose a diversification of their activities (thus of the land use), in order to reduce aggregate risk (Morduch, 1995; Godoy et al., 1998). Some studies analyze this use of NTFP (Baland and Francois, 2004; Pattanayak and Sills, 2001). One of the results is that any individual is more likely to visit the forest if the crops are more risky or if he faces a negative shock. Godoy et al. (2000), in a study in Honduras, argue that although NTFP extraction has a low annual value, it can provide insurance in the case of unexpected losses. This risk-management role can be particularly important in the case of common risk, because intra-village credit or insurance systems are more difficult to implement (Dercon, 2002).

Two risk-management strategies may be implemented (Angelsen and Wunder, 2002). The diversification strategy (usually observed in Latin America) is a classic risk-management tool (Aldermann and Paxson, 1994). The household raises ex ante the number of its activities, 
choosing if possible activities that have low covariance. In contrast, the coping strategy (observed in Africa) consists of extracting NTFP only in the case of bad agricultural crops. The use of NTFP can here be considered as an ex post gap filling use. Forest products are extracted in order to smooth the household's consumption in case of low crop returns.

In these two risk-management approaches, NTFP extraction appears to be efficient for poor rural households. First, a large variety of NTFP can be extracted, thus raising the diversification of activities. Several studies mention fuel, fodder, fibres, oil seeds, edible fruits, staple foods, vegetables, spices, rope, leaf-plates, medicinal plants, vines, honey, sap, Brazilian nuts, fruits bark and rubber (Kumar (2002), for rural India; Pattanayak and Sills (2001), for the Tapajos National Forest, Brazilian Amazon). Second, many NTFP do not have strong positive correlation among themselves or with agricultural output (Pattayanak and Sills, 2001), so that they can be efficient risk-management instruments. A bad agricultural output is not necessarily linked to bad forest product quantities.

Two characteristics of NTFP are important to note. First, there are low capital and skills requirements to NTFP extraction as well as open or semi-open access to the resource, so that poor households can easily extract the resource. Neumann and Hirsch (2000) argue that the poorest people are those who are the most engaged in NTFP extraction. Second, NTFP habitually have low return to labor, so that they have poor potential to alleviate poverty (Wunder, 2001; Angelsen and Wunder, 2002). Studying Bagyeli and Bantu communities in South Cameroon, Van Dijk (in Ros-Tonen and Wiersum (2003)) gives an illustration of the relatively low share of NTFP in total income -which argues for the risk-management strategies- and of the link between poverty and NTFP use.

Hence, forests are competing for the land-use, with agriculture representing the most important alternative. Indeed, forest products have a low potential of poverty alleviation, but can be used to compensate shortfalls in agricultural yields. Conversely, agricultural crops is a potential way out of poverty for households, but may represent a high levels of risk, especially if the households have low access to insurance or credit markets. The trade-off between these two land-uses is a major choice for poor rural households, and is a potentially driving force of deforestation. An interesting topic is thus to analyze the land-use choice process of the households. 


\subsection{The land-use choice literature and NTFP extraction}

Among the papers studying the land-use choice by rural communities, only few take into account the forest products use, and none study the risk-management use described here. Lopez (1998) notes the coexistence in most developing countries of private lands, intended for agricultural crops, and common property lands, namely forests, used for their products. In his paper, the two land-uses compete with each other, but forest products extraction is not a risk-management strategy. Specifically, Lopez analyzes the consequences of agricultural intensification and farm productivity improvement programs on the pressures on the common resource. The main factor determining the programs' impact on pressure on the common resource is the factor-intensity of the crops. If crops are labor-intensive, then a rise in their prices is likely to diminish the pressure on the common resource. However, if crops are land-intensive, the pressure is likely to rise with the commodity prices.

Parks et al. (1998) study the competing land-uses, mainly agriculture, timber and nontimber forest products. The paper distinguishes four cases, depending on the relative productivity of the different activities: joint management of forests, forest preservation, conversion to non-forest use, and forest abandonment. These four cases depend mainly on the impact of the age of the trees and the management effort on a profit maximization function.

\subsection{Common property resources as safety net}

The literature on land-use choice discussed above ignores the safety-net role that forests have when they are commonly held. Another part of the literature does, however, argue the importance of common property resources (CPR) as safety net. Baland and Francois (2005) analyze the insurance property of CPR, and compare it with the increased efficiency if this resource is privatized. In their paper, each household has the choice between two activities: CPR extraction and a private project. CPR extraction requires low skilled labor, which implies homogenous returns to labor. The private projects provide heterogenous returns, depending on the households skills. Therefore, CPR extraction represents for low skilled households an outside option to private project, while the most skilled households allocate their labor to the private projects. The authors found a potential negative impact of the privatization of the resource on the welfare of the community's poorest members. 
Pattanayak and Sills (2001) find that NTFP collection is positively correlated with agricultural shortfall and expected agricultural risk. According to Bromley and Chavas (1989), non-exclusive property rights can be seen as an integral part of risk sharing. In this case, the common forest can be considered as an asset of last resort (Baland and Francois, 2005). A strong link between poor people and CPR is often underlined. Dasgupta and Maler (1993) argue that local commons provide the rural poor with partial protection in time of unusual economic stress. A study of tribal groups in rural Bihar qualifies communally-held forests as the only means of survival for poorer members in lean seasons (Agrawal, 1991). Reddy and Chahravaty (1999) observe in India a more intensive use of the CPR by poor households. Dasgupta (1987) notes a higher level of CPR products in low labor productivity regions. Johda (1986) finds a negative relationship between CPR income and rural inequalities.

Although some papers study the competing land-use relationship between agriculture and forests, none of them investigate the safety-net use of forest products to insure against crops risk. In contrast, papers studying the safety-net role of CPR treat the share private/common land as exogenous. The aim of this paper is thus to reconcile these two sides of the literature, investigating the role of the safety-net use of NTFP on the land-use choice.

\section{Diversification strategy, risk-aversion and house- hold's optimal land-use}

The model presented is an adaptation from Angelsen (1999). In contrast to Angelsen's setup, agricultural output is uncertain and forest provides NTFP that are used to smooth the household's consumption when the agricultural output is bad.

The set-up for the land: The model represents a village economy. The total area of the village is normalized to 1 . We assume here only two possible uses for the land: agriculture and forests. Both agricultural and forested areas are assumed to have the same quality. In contrast to Angelsen (1999), we assume that forests provide Non-Timber Forest Products (NTFP). We assume for simplicity an egalitarian repartition of the land across the households in the village. Therefore, we consider a representative household, which has a share $\frac{1}{N}$ of the total area of the village ( $\mathrm{N}$ is the number of households in the village and is our indicator 
of population pressure), which is equivalent to a share $\frac{1}{N}$ of total forest product extraction. We avoid thus the tragedy of the commons problem, i.e competition between households for the forest products. We also assume that both the agricultural good and the forest product are homogenous. For both goods, land and labor are the only inputs. We assume that the household uses an optimal combination of labor in the production process. Thus the labor side is not explicitly considered here. The implicit assumption is that the household's labor force is entirely used and that the household may eventually hire outside labor ${ }^{3}$.

$\mathrm{R}$ is the share of agricultural land in the village area $(0 \leq R \leq 1)$. Agricultural land area used by the household is thus defined as $\frac{R}{N}$ and forest land area for the representative household use is $\frac{1-R}{N}$. $\mathrm{R}$ is an indicator of the agricultural land cover and the choice variable of the household. At the beginning of the period, the household chooses the share of the land it will cultivate. If $R=1$, all the land around the village is converted to agriculture and deforestation is maximized in the village area. If $R=0$, forest conservation is maximized and there is no agriculture. Between these two extreme cases, there is a trade-off between the two possible uses of the land.

The safety-net use of forest products: We focus here on the diversification strategy, i.e. the land-use choice (inducing the labor allocation) is made ex ante. We assume that agricultural land is, on average, more profitable than forest land, but agricultural production is more volatile than NTFP. Thus, there is a trade-off between a relatively more profitable but riskier activity - agriculture - and a relatively less profitable but safer activity - NTFP extraction. In contrast to Angelsen (1999), the agricultural output is not certain. The risk on agricultural crops is supposed to be systemic. Therefore every household in the village lives in the same state of the world. Thus there cannot be inter-household insurance.

There are two states of the world. In the good state, which occurs with probability $\delta$, the agricultural output per hectare (or per unit of land, as the area is normalized to 1) is high.

$$
\bar{C}(R) \equiv \frac{1}{N}[R \bar{x}+(1-R) f]
$$

\footnotetext{
${ }^{3}$ For an analysis of the interactions between labor market and deforestation, see Bluffstone (1995).
} 
where $\bar{x}$ is the optimal agricultural output (net of costs) per hectare in the good state of the world. $\mathrm{f}$ is the quantity of forest products extracted per hectare, net of extraction costs. In contrast to the agricultural output, $\mathrm{f}$ is assumed to be certain.

In the bad state, with probability $(1-\delta)$, agricultural output is low.

$$
\underline{C}(R) \equiv \frac{1}{N}[R \underline{x}+(1-R) f]
$$

$\underline{x}$ is the optimal agricultural output in the bad state of the world. Clearly $\underline{x}<\bar{x}$ must hold. Expected agricultural output per hectare is therefore:

$$
E(x)=\delta \bar{x}+(1-\delta) \underline{x}
$$

Clearly, by assumption $f<E(x)$, for otherwise there is no trade-off between the two land-uses and all the land is used for forest product extraction.

\subsection{Expected utility maximization}

The objective of the household is to maximize its expected utility. The household's utility function only depends on consumption: $U=U(C)$, with $\frac{\partial U}{\partial C}>0$. A quick mean-variance analysis may be done before considering the household's optimal trade-off.

Mean-variance analysis: Both the expected level of consumption and its variance depend on the share of agricultural land, R, to be chosen by the household.

The household can either consume directly what it produces or sell it to purchase other goods. Thus we consider the equality between consumption and production as a budget constraint. The expected level of consumption is therefore:

$$
E_{c}(R)=\frac{1}{N}[R(E(x)-f)+f] ; \quad \frac{\partial E_{c}(R)}{\partial R}>0
$$

Expected consumption rises with the share of agricultural land, R, since expected agricultural production is more efficient than forest product extraction. Therefore, a risk-neutral household would convert all the land into fields $(R=1)$ in order to maximize its expected consumption. The variance of consumption is:

$$
\sigma_{c}^{2}=\frac{1}{N^{2}} \sigma_{x}^{2} R^{2}
$$


Clearly the variance of consumption is strictly increasing in $\mathrm{R}$. Thus the choice in the land-use is a trade-off between expected consumption and variance of consumption. The relative weight given to the expected consumption and the variance will depend on its riskaversion: a risk-averse household gives more importance to the variance of consumption, than a risk-neutral household.

Household's objective and the optimal trade-off: We introduce a Constant Absolute Risk Aversion (CARA) function, with $\alpha$ being the Arrow-Pratt Absolute Risk Aversion coefficient:

$$
U(C)=-\exp [-\alpha C]
$$

Expected utility is then:

$$
E_{U}(R)=-\delta \exp [-\alpha \bar{C}(R)]-(1-\delta) \exp [-\alpha \underline{C}(R)]
$$

The objective of the household is to choose $\mathrm{R}$ in order to maximize expected utility:

$$
\max _{R} E_{U}(R)
$$

Note that $\frac{\partial E_{U}}{\partial R}>0$ if $f \leq \underline{x}$. Therefore, we have a corner solution $(R=1)$ if the forest profitability is lower than or equal to the agricultural profitability in the bad state of the world. In this framework, the safety-net use of the forest products only exists if the risk on agricultural output is so high that NTFP extraction becomes the main activity of the household in the bad state of the world. This condition is consistent with a portfolio analysis, where the risk-free asset needs to be more profitable than the risky asset in some states of the world to have a positive share in the portfolio (Gollier, 2001). We now characterize the agricultural frontier that maximizes expected utility. The first-order condition gives the optimal agricultural frontier:

$$
R^{*}=\left(\frac{N\left[\ln \frac{\delta(\bar{x}-f)}{(1-\delta)(f-\underline{x})}\right]}{\alpha(\bar{x}-\underline{x})}\right)
$$

\subsection{Comparative statics}

In this framework of risk on agricultural output, we define risk reduction as a rise in $\underline{x}$ and a fall in $\bar{x}$, with a constant expected output $E(x)$. This kind of risk reduction can be viewed 
as the introduction of an insurance system. On the one hand, the household pays a risk premium $d \bar{x}$ per hectare in the good state of the world. On the other hand, if the bad state of the world occurs, the household receives as insurance $d \underline{x}$ per hectare. This risk reduction definition implies $(1-\delta) d \underline{x}=-\delta d \bar{x}$, with $d \underline{x}>0$.

Proposition 1 : When NTFP extraction is used as a diversification strategy, risk reduction, lower risk aversion and larger population decrease the forest cover. Moreover, the forest profitability is positively correlated with the forest cover.

Proof : sign of the first derivatives of $R^{*}$ (see appendix A): $\quad\left(\frac{\partial R^{*}}{\partial \underline{x}}-\frac{(1-\delta)}{\delta} \frac{\partial R^{*}}{\partial \bar{x}}\right)>0$, $\frac{\partial R^{*}}{\partial \alpha}<0, \quad \frac{\partial R^{*}}{\partial N}>0$ and $\frac{\partial R^{*}}{\partial f}<0$.

Risk reduction has a positive impact on $\mathrm{R}$. Hence, if the agricultural risk is reduced, the safety-net use of NTFP is less important, agricultural land increases and forest cover declines. Intuitively, if the more profitable activity becomes less risky - with the same expected profitability -, its share in the agent's portfolio raises. In our example, the introduction of an insurance mechanism thus leads to more deforestation.

The Arrow-Pratt Absolute Risk Aversion coefficient has a positive impact on the forest cover. Intuitively, if the household is risk averse, it keeps more land as forest in order to insure itself against crop risks, even if this is done at the expense of lower expected consumption.

The village population has a negative impact on the forest cover (positive impact on R). Indeed, a larger population reduces the size allowed to each household. Each household therefore raises the share of the most profitable activity.

Consistently with a portfolio analysis, the portfolio share of the risk-free asset, i.e. NTFP extraction, is positively correlated with its profitability. A rise in forest profitability could come, for example, from a rise in the NTFP prices. A policy frequently advocated to reduce tropical deforestation is the introduction of green labeling for NTFP in order to raise the profitability of the forests. Appendix $\mathrm{C}$ provides a numerical example of the coping and diversification strategies.

The precedent proposition ignores the fact that NTFP extraction from a common property or free access forest can constitute a poverty trap, as an extreme case of a tragedy-ofthe-commons process. This case is studied in the next section. 


\section{Safety-net or poverty trap?}

In this section, we build on Baland and Francois (2005). The share of agricultural land (R) is now supposed to be fixed, and not a choice variable anymore. The choice variable is now the allocation of labor between the two activities. Moreover, the households are supposed to have different productivity on the agricultural land. We distinguish therefore skilled and unskilled households. In contrast to the precedent section and because of household heterogeneity, only unskilled households allocate some labor to CPR extraction.

The $\mathrm{N}$ households of the community allocate their unit of labor $\left(L_{i}=1\right)$ between two activities. First, labor can be allocated to a private project (e.g: private agriculture). Second, it can be allocated to CPR extraction (e.g: NTFP extraction). In Baland and Francois, the household allocate all its labor to one activity. In contrast, in the following model, each household can divide its labor supply and allocate a share to both activities.

Baland and Francois consider successively a risk-free private project with heterogeneous returns, and a risky private project with homogeneous returns. Conversely, we consider here a risky private project with heterogeneous returns, while the CPR provides safe and homogeneous returns. Therefore, CPR extraction may have two motivations. First, households have different expected returns on their private project and the less skilled households allocate all their labor to CPR extraction, and the CPR returns represent the minimum income of the community. Second, the households face also different levels of risk on their private projects and allocate thus a share of their labor supply to CPR extraction in order to insure themselves (note here that we assume the extreme case of no outside insurance possibilities). Whereas Baland and Francois consider separately those two kinds of heterogeneity, the model presented here study the possible poverty-trap implications of the coexistence of these two role of the CPR: minimum income and insurance.

\subsection{NTFP extraction as insurance and households heterogeneity}

As in Baland and Francois (2005), we assume that all labor allocated to the CPR is equivalently productive and receives the average product: $\frac{f(L) . l_{i}}{L}$, with $l_{i} \in[0,1]$ the amount of labor allocated to the CPR by household $i$ and $L=\int_{N}^{1} l_{i} d i$ the aggregate amount of labor 
allocated to the commons ${ }^{4}$. The commons production function, $f(L)$, is strictly increasing and concave in L. Therefore, the average product is decreasing in L, which constitutes a tragedy-of-the-commons effect: labor allocated by one household has a negative externality on the other households. Moreover, total labor allocated to the commons can be an indicator of environmental damages. Indeed, the overuse of a resource coincides with the degradation of the ecosystem. Note here that we assume that the CPR is de facto open access, and that no joint management strategy is implemented to induce sustainable use.

As already said, the private projects provide uncertain returns ${ }^{5}$. The expected private project return of household $i$ is $E\left(x_{i}\right) .\left(1-l_{i}\right)$. In the worst case, the private project provides $\underline{x_{i}} .\left(1-l_{i}\right)$. Note here that only $E\left(x_{i}\right)$ and $\underline{x_{i}}$ (and not the whole distribution of the private project returns) are needed to describe the households characteristics. We restrict ourselves to the case of common risk, i.e. we define: $\underline{x_{i}}=E\left(x_{i}\right)-C$. Where $\mathrm{C}$ is the same across households. Expected returns, $E(x)$, and minimum returns, $\underline{x}$, constitute a representation of the households heterogeneity in terms of skills and risk, respectively.

The households are sorted according to the expected return on their private project. Household 1 has the lowest expected return and household $N$ has the highest one.

Household's objective: At the beginning of the period, each household chooses its labor allocation between the two activities to maximize its expected return $\Pi\left(l_{i}\right)$ :

$$
\max _{l_{i}} \Pi\left(l_{i}\right)=\left(1-l_{i}\right) \cdot E\left(x_{i}\right)+l_{i} \cdot \frac{f(L)}{L}
$$

Moreover, the households need to insure a minimum consumption requirement $C_{\min }$ in the worst state of the world (i.e if $\underline{x_{i}}$ occurs). We assume here that the minimum requirement is the same across the population. We consider basic needs to survive, such as nutrition. If this requirement is not met, concerned households cannot stay in the community and have therefore to migrate. Migration is therefore considered here as an action of last resort if the environment cannot insure their livelihood to some households. An important concern here is whether migration provides the minimum requirement to migrating households. Indeed, migrating is by itself a risky behavior. This concern is not explicitly considered here. The

\footnotetext{
${ }^{4}$ Note here that the size of the CPR is fixed, and therefore not a choice variable.

${ }^{5} \mathrm{~A}$ first-best outcome would therefore come from the introduction of an efficient insurance market that eliminate risk on the private project.
} 
important point is that some households have to migrate simply because their livelihood is threatened.

The choice of any household i to migrate $\left(M_{i}=1\right)$ or not $\left(M_{i}=0\right)$, is therefore:

$$
\left\{\begin{array}{l}
M_{i}=1 \text { if }\left(1-l_{i}\right) \cdot \underline{x_{i}}+l_{i} \frac{f(L)}{L}<C_{\text {min }} \\
M_{i}=0 \text { if }\left(1-l_{i}\right) \cdot \underline{x_{i}}+l_{i} \frac{f(L)}{L} \geq C_{\text {min }}
\end{array}\right.
$$

Thus households are risk neutral, as long as they get their minimum requirement, and are infinitely risk averse under that point. We define as poor a household not getting more than its subsistence requirement: it cannot get more from its activities than what it needs to survive. This set up is somehow unfamiliar, but seems to fit with the reality of many poor communities of developing countries. Indeed, the main objective of poor households is likely to insure livelihood. Thus, it seems fair to assume that, in very poor communities, households first insure their livelihood, and then try to maximize their expected payoff.

Two kinds of households decide not to migrate. First, private projects may be profitable enough for some households, even in the worst state of the world: $\underline{x_{i}} \geq C_{\min }$. These households are naturally insured. Second, households properly insured by CPR extraction also decide not to migrate. Thus CPR extraction needs to be profitable enough to insure the households properly, and the households need to allocate a minimum amount of labor to the CPR. The conditions for these households to stay in the community are as follow.

$$
\left\{\begin{array}{l}
\frac{f(L)}{L} \geq C_{\min } \\
\underline{l_{i}}=\frac{C_{\min }-\underline{x_{i}}}{\frac{f(L)}{L}-\underline{x_{i}}}
\end{array}\right.
$$

Return to CPR extraction is decreasing in total labor allocated. Thus, if too much labor is allocated to the CPR, the average product goes down to its bottom value $C_{\min }$. Therefore, a maximum possible amount of labor allocated to the CPR can be defined:

$$
L_{\max }: \frac{f\left(L_{\max }\right)}{L_{\max }}=C_{\min }
$$

If too many households are in need of insurance, the insurance capacity of the resource, $L_{\text {max }}$, may be too small. At this point, some households have to migrate and migration occurs until the point at which every remaining household is insured, with the average return being equal to the minimum requirement. Migration is considered here as an action of last resort: the environment cannot provide to the households their livelihood, thus they have to leave. 
Households are therefore assumed to migrate from the area if and only if they cannot get their minimum requirement from their livelihood. The number of households having to migrate is therefore:

$$
M=\int_{0}^{N} M_{i} d i=S-L_{\max }
$$

with $\mathrm{S}$ the population in need of insurance:

$$
S: \underline{x}_{S}=C_{\text {min }}
$$

At equilibrium, three classes of households can be distinguished, related to their labor allocation.

\subsection{Classes of households at equilibrium}

The equilibrium is a combination of a total amount of labor allocated to the commons, $L_{c}$, a share of labor allocated to the commons by each household, $l_{i}$, and a number of households that have to migrate, $\mathrm{M}$.

At equilibrium, 3 classes of households can be distinguished according to the households allocation of labor. Two classes are in need of insurance and therefore allocate a share of their labor to CPR extraction, while the third one is "naturally" insured.

Unskilled households: The less skilled households have an expected return on the private project smaller or equal to the average product on the CPR. These households allocate all their labor to the CPR. Therefore they get the average product.

$$
\text { For } i \in[0 ; U]:\left\{\begin{array}{l}
E\left(x_{i}\right) \leq \frac{f\left(L_{c}\right)}{L_{c}} \\
\underline{x_{i}}<C_{\text {min }} \\
l_{i}=1 \\
\Pi\left(l_{i}\right)=\frac{f\left(L_{c}\right)}{L_{c}}
\end{array}\right.
$$

The motivation for CPR extraction here is a lack of better opportunity. Less skilled households rely on this activity because it requires low skilled labor and provides higher returns than their private projects. 
Skilled households: The most skilled households are those who get at least their minimum requirement from their private project. Moreover, the expected return on their private project must be greater than the average product on the CPR. Thus they allocate all their labor to the private project. Their expected income is the expected private return.

$$
\text { For } i \in[S ; N]:\left\{\begin{array}{l}
E\left(x_{i}\right)>\frac{f\left(L_{c}\right)}{L_{c}} \\
\underline{x_{i}} \geq C_{\text {min }} \\
l_{i}=0 \\
\Pi\left(l_{i}\right)=E\left(x_{i}\right)
\end{array}\right.
$$

This class of household can be considered as "naturally" insured: they always get enough returns from their private project to satisfy their basic needs.

Middle class: This last class of household does not appear in Baland and Francois. For this class, the private project is in expectation more profitable than CPR extraction. However, there are some states of the world in which this private project does not provide their minimum requirement. Therefore they put some labor in CPR extraction in order to insure themselves. Because the expected private project return is greater than the return on CPR extraction, these households allocate labor on the CPR in order to get exactly their minimum requirement in the worst state of the world.

$$
\text { For } i \in[U ; S]:\left\{\begin{array}{l}
E\left(x_{i}\right)>\frac{f\left(L_{c}\right)}{L_{c}} \\
\underline{x_{i}}<C_{\min } \\
l_{i}=\frac{C_{\min }-\underline{x}_{i}}{\frac{f\left(L_{c}\right)}{L_{c}}-\underline{x}_{i}} \\
\Pi\left(l_{i}\right)=l_{i} \cdot \frac{f\left(L_{c}\right)}{L_{c}}+\left(1-l_{i}\right) \cdot E\left(x_{i}\right)
\end{array}\right.
$$

While in a world with perfect insurance, these middle-class households would allocate all their labor to the private project and get its expected return, they need here to extract from the CPR in order to insure themselves, at the expense of reducing their expected return. Note here that $S$ represents the population in need of insurance (unskilled and middle class). The following table synthesizes the patterns of the different classes in equilibrium. 


\begin{tabular}{|c|c|c|c|}
\hline & Unskilled & Middle & Skilled \\
\hline Households & {$[0 ; U]$} & {$[U ; S]$} & {$[S ; N]$} \\
\hline$E\left(\theta_{i}\right)$ & $\leq \frac{f\left(L_{c}\right)}{L_{c}}$ & \multicolumn{2}{|l|}{$>\frac{f\left(L_{c}\right)}{L_{c}}$} \\
\hline$\underline{\theta_{i}}$ & \multicolumn{2}{|r|}{$<C_{\min }$} & $\geq C_{\text {min }}$ \\
\hline$l_{i}$ & 1 & $\underline{l_{i}}$ & 0 \\
\hline$\Pi\left(l_{i}\right)$ & $\frac{f\left(L_{c}\right)}{L_{c}}$ & $\underline{l_{i}} \cdot \frac{f\left(L_{c}\right)}{L_{c}}+\left(1-\underline{l_{i}}\right) \cdot E\left(x_{i}\right)$ & $E\left(x_{i}\right)$ \\
\hline
\end{tabular}

In order to show how CPR extraction becomes a poverty trap, we need to determine what is the total amount of labor in the CPR.

\subsection{Total amount of labor in the CPR}

Only two classes of household allocate labor to CPR extraction: the unskilled and the middle class. First, the unskilled households allocate all their labor to the CPR. Note here that the number of households classified in the unskilled class depends on the total amount of labor allocated to the CPR.

$$
\left\{\begin{array}{l}
L_{c}^{U}\left(L_{c}\right)=\int_{1}^{U\left(L_{c}\right)} 1 d i=U\left(L_{c}\right) \\
U\left(L_{c}\right): E\left(x_{U}\right)=\frac{f\left(L_{c}\right)}{L_{c}}
\end{array}\right.
$$

Second, the middle-class households allocate only a share of their labor supply to the CPR.

$$
\left\{\begin{array}{l}
L_{c}^{M}\left(L_{c}\right)=\int_{U\left(L_{c}\right)}^{S}\left[\frac{C_{\min }-\underline{\theta}_{i}}{\frac{f\left(L_{c}\right)}{L_{c}}-\underline{x}_{i}}\right] d i \\
S: \underline{x}_{S}=C_{m i n}
\end{array}\right.
$$

$\mathrm{S}$ therefore represents the population in need of insurance. The size of the population in need of insurance is independent of the total amount of labor allocated to the CPR. However, the total amount $L_{c}$ influences the repartition between unskilled and middle-class households.

CPR extraction constitutes a poverty trap if the average product of CPR extraction go below the minimum requirement. In this case, CPR extraction cannot properly insure the households. This situation occurs if too much labor is allocated to the CPR: $L>L_{\max }$. In that case, both poor and middle-class households cannot get more than their minimum requirement and allocate all their labor to CPR extraction. Moreover, M households have to migrate until the average return $\frac{f\left(L_{c}\right)}{L_{c}}$ equals the minimum requirement $C_{\text {min }}$. 
Thus, if CPR extraction does not constitute a poverty trap, the equilibrium amount of labor allocated to the $\mathrm{CPR}$ is:

$$
\left\{\begin{array}{l}
L_{c}=L_{c}^{U}+L_{c}^{M} \\
\frac{f\left(L_{c}\right)}{L_{c}}>C_{\min } \\
M=0
\end{array}\right.
$$

Note here that the total amount of labor allocated to the CPR in the non-poverty-trap case is a fixed point of which the existence needs to be proven (see appendix C).

The equilibrium amount of labor allocated to the CPR in the poverty trap case is:

$$
\left\{\begin{array}{l}
L_{c}=L_{\max } \\
\frac{f\left(L_{c}\right)}{L_{c}}=C_{\min } \\
M=S-L_{\max }
\end{array}\right.
$$

At this point, it is possible to describe the two types of situation.

\subsection{Tragedy of the commons and poverty trap}

It is well known that an open-access resource suffers of a tragedy of the commons: individuals do not take into account the negative externality of their actions on the others. In the case studied here, with CPR used as insurance, this phenomenon may lead to a poverty trap: the population in need of insurance (unskilled and middle class households) is trapped in CPR extraction and cannot get more than their minimum requirement. Moreover, some households have to migrate.

Insurance without poverty trap: We consider here the case where: $L_{c} \geq L_{\max }$. Therefore, the insurance use of the CPR does not lead to a poverty trap. Nevertheless, CPR extraction is characterized by a tragedy-of-the-commons process. Note for example that both unskilled and middle class households would be better off with an insurance scheme. Indeed, middle class households could allocate all their labor to their private project, which is more profitable in expectation. Moreover, the unskilled households would be better off too, because the labor supply allocated to the commons and thus the tragedy-of-the-commons effect would be lower. Therefore, the average product of CPR extraction would be bigger. Figure 1 illustrate this case. 


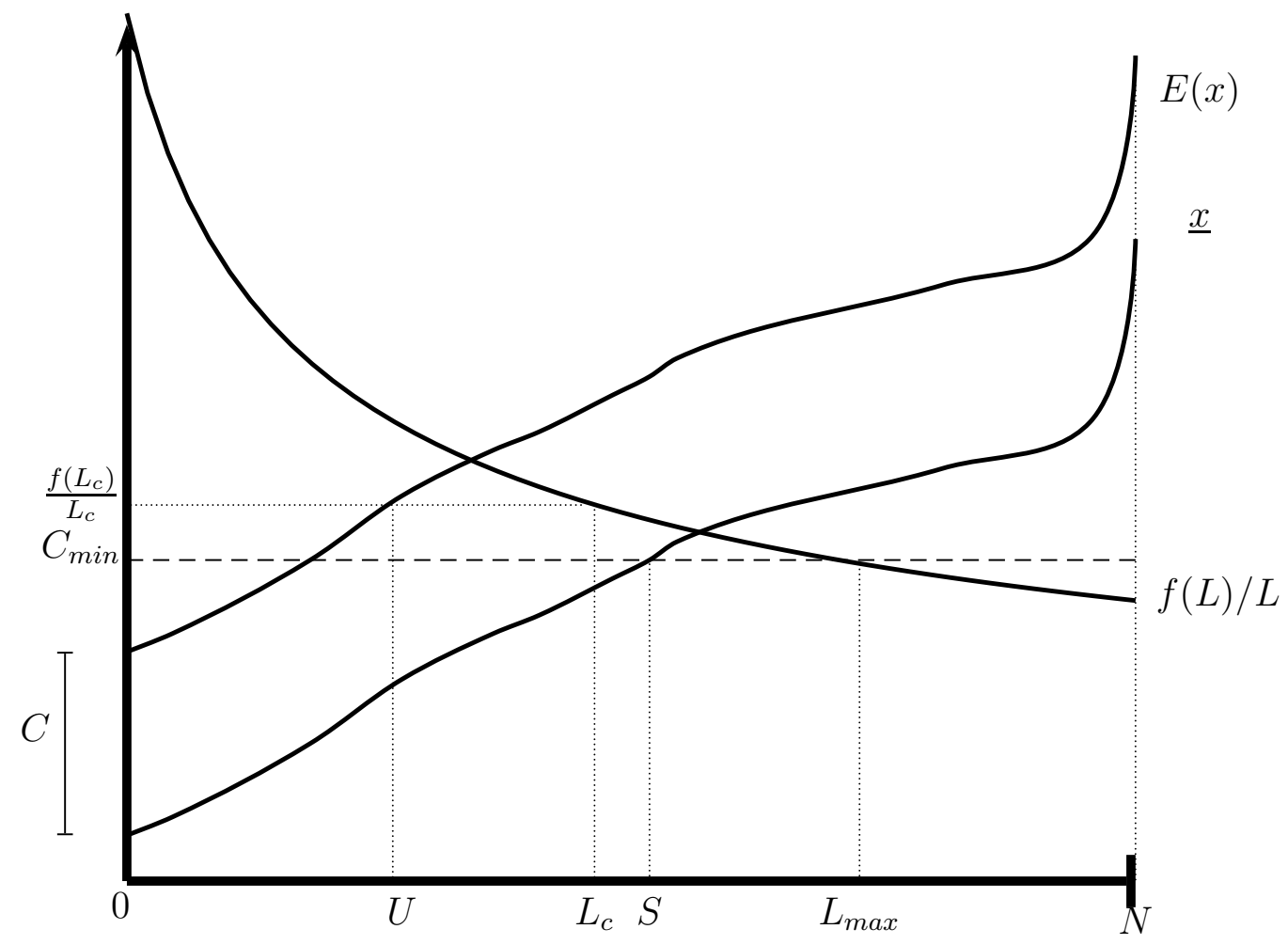

Figure 1: Insurance with no poverty trap and common risk

Insurance with poverty trap The poverty-trap case is a result of: $S>L_{c}=L_{\max }$. More precisely, it is essentially an extreme consequence of the tragedy of the commons described before. As already showed, $\mathrm{M}$ households have to migrate until the point at which the average product of $\mathrm{CPR}$ extraction reach the minimum requirement. At this point, middle class households have to allocate all their labor to the CPR in order to insure themselves. Therefore, both unskilled and middle class households are perfectly insured but cannot get more than their minimum requirement, which constitute a poverty trap (as defined in introduction). Figure 2 describes the poverty trap case. Note here that skilled households get the same outcome whatever is the type of situation. 


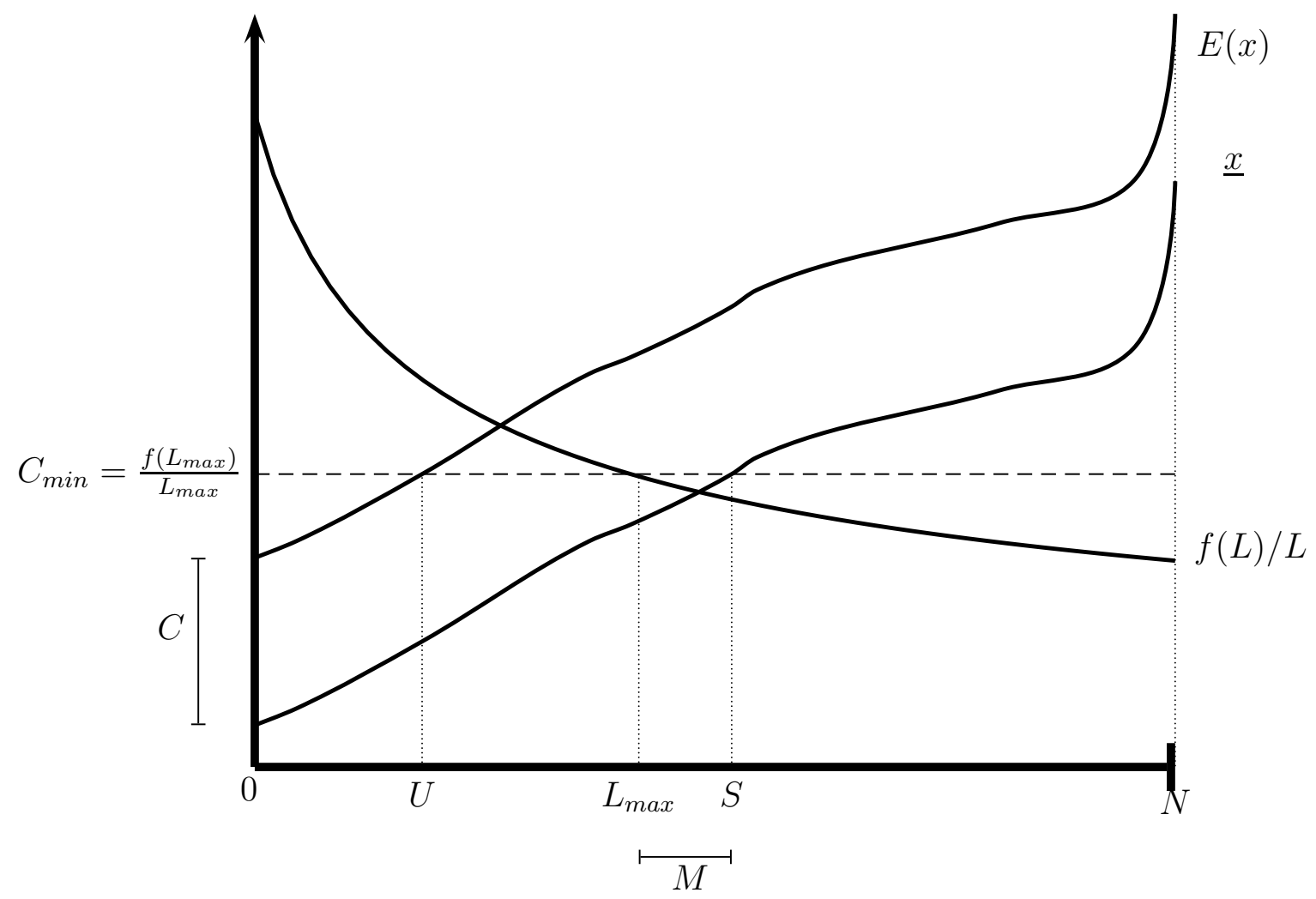

Figure 2: Insurance with poverty trap and common risk

The causes of the poverty trap: A poverty trap is therefore the result of two main factors. First, population factors are important. If the population in need of insurance $(S)$ is big, the poverty trap case is more likely. The size of this population is a consequence of two components: distribution of skills $(E(x))$ and distribution of risk $(\underline{x})$. Firstly, the bigger is the population with relatively high expected return on the private profit, the smaller is the unskilled population. Secondly, the smaller is the risk at which the households are exposed, the bigger is the population that does not depend on the resource.

Second, the production function of the CPR determines the threshold of population $\left(L_{\max }\right)$ that could exploit it. If the environment is fragile, it is quickly saturated and the threshold is low.

Proposition 2: In a context of risk on the private projects, such as agriculture, the use of CPR extraction as insurance can lead to a poverty trap if the population in need of insurance is too large and the resource has small capacity. Then, both unskilled and middle 
class households are trapped in CPR extraction and cannot get more than their basic needs in return.

Proof: A poverty trap situation is characterized by: $L_{c}=L_{\max }$. S determine the equilibrium amount of labor allocated to the $\mathrm{CPR}\left(L_{c}\right)$, while the capacity of the resource determine the production function, and thus the maximum amount of labor allocated to the $\operatorname{CPR}\left(L_{\max }\right)$.

As already mentioned, the poverty-trap situation is an extreme case of a tragedy of the commons. The only difference in terms of welfare between those two cases is the fact that the middle class de facto disappears when CPR extraction becomes a poverty trap. Indeed, middle class households can insure themselves only at the cost of allocating all their labor to the CPR. They lose therefore all the extra return they could get from their private project. Only two classes of households remain in the society: the unskilled and the skilled households.

Moreover, as shown in Baland and Francois (2005), privatization may not be a good solution in terms of welfare, since the improved efficiency may not compensate for the reduction of the insurance properties of the CPR.

\section{Conclusion}

The aim of this paper is to investigate the safety-net function of forest products in the economics of land-use change and deforestation. We analyze the trade-off between two land-uses. Agriculture is more profitable but is risky. In contrast, NTFP extraction is less profitable but is used to smooth consumption or to fill some consumption gaps when agricultural crops are bad.

The first model presented ignores some important features of poor agricultural households, which open opportunities for future research. First, households may compete for NTFP extraction if the forest is open access. The potential poverty-trap implications that NTFP extraction may create must then be taken into account. Indeed, if the population in need of safety net is large, and if the forest capacity is small, a tragedy-of-the-commons process may trap the less skilled households into NTFP extraction and deprive them of 
other development opportunities. The second model of the paper highlight this potential implication.

Second, considering more explicitly labor market integration could point outside opportunities for households, that would reduce the safety-net role of NTFP extraction and thus increase deforestation. Third, other types of risk-management could have several implications on the land use. For example, agricultural households could use livestock as a risk-management strategy, which could increase land clearing and deforestation. Fourth, the statement of risk-free NTFP extraction should be moderated, because of the existence of risk such as animal migration or price volatility. Finally, the two models presented are static, while dynamic modeling could allow for accumulation as insurance.

However, although quite simple and not considering some important factors such as dynamic effects or labor outside options, the model presented here stresses some important implications. We predict that a reduction in crop risk may have a negative impact on forest cover. Development policies often consider agricultural development as a priority. Moreover, an important objective is to reduce risk on poor agricultural households' income. Therefore, to reduce this impact, risk reduction policies should be combined with environmental and forest management policies. For example, payment for environmental services provided by forests may be an interesting tool. Indeed this kind of payment may enhance forest preservation and raise the "profitability" of forests.

Risk aversion of the household is positively correlated with forest cover. This result is quite intuitive, since forest products are a tool to reduce risk. In the economic analysis, households are typically more risk averse than entrepreneurs, generally risk neutral. Economic development may raise through market integration the separability between the utility and profit maximizing process. Households may become less risk averse, which could have a negative impact on forest cover. Moreover, market integration should provide to households new insurance and credit mechanisms, reducing the safety-net use of forest products described in this paper. This kind of market integration can thus indirectly lead to more deforestation.

Agricultural risk and the safety-net use of NTFP extraction is therefore an crucial issue with important economic and environmental implications such as deforestation, poverty-trap and degradation of commonly-held forests. Some empirical analysis of the relationships that 
link agricultural risk, poverty and deforestation could give interesting indications. Moreover, a natural extension of this paper would be to allow for land-use and labor allocation to be choice variables at the same time.

Finally a related issue is the study of potential conflicts of interest between local communities using the resource and forest loggers. In this context, corruption and lobbying powers have an important role, that could lead, for the local communities, to the deprivation of the resource.

\section{Acknowledgements}

I thank my supervisors, Rick van der Ploeg and Pascal Courty, for their helpful advice. I also acknowledge useful comments from Arild Angelsen, Aart de Zeeuw, Timo Goeschl, two anonymous reviewers and an Environment and Development Economics associate editor.

The first part of this paper has been published in Environment and Development Economics (issue 12-02, April 2007), and presented at the "14th Annual Conference of the European Association of Environmental and Resource Economists" (Bremen, June 2005) and at the EAERE - FEEM - VIU Summer School in Environmental Economics (Venice, July 2005). I thank the participants for comments.

The second part of this paper has been presented at a LAMETA-INRA seminar (June 2006) and at the 8th Annual BioEcon Conference (Kings College Cambridge, August 2006). It is forthcoming in Environment and Development Economics.

I am grateful to the Lavoisier programme for financial support.

\section{Appendix A: comparative statics}

Proof of proposition 1: we take the first derivatives of the optimal share of agricultural land $R^{*}$ with respect to our variables of interest. We define a risk reduction as a rise in $\underline{x}$ 
and a fall in $\bar{x}$, with a constant expected output $E(x):(1-\delta) d \underline{x}+\delta d \bar{x}=0 ; d \underline{x}>0 ; d \bar{x}<0$.

$$
\begin{aligned}
\left(\frac{\partial R^{*}}{\partial \underline{x}}-\frac{(1-\delta)}{\delta} \frac{\partial R^{*}}{\partial \bar{x}}\right) \cdot d \underline{x} & =N \frac{\left[\ln \left(\frac{\delta(\bar{x}-f)}{(1-\delta)(f-\underline{x})}\right)+\frac{(\bar{x}-\underline{x})(E(x)-f)}{\delta \alpha(\bar{x}-f)(f-\underline{x})}\right]}{\delta} \cdot d \underline{x}>0 \\
\frac{\partial R^{*}}{\partial \alpha} & =\frac{-N \ln \left[\frac{\delta(\bar{x}-f)}{(1-\delta)(f-\underline{x})}\right]}{\alpha^{2}[\bar{x}-\underline{x}]}<0 \\
\frac{\partial R^{*}}{\partial N} & =\frac{\ln \left[\frac{\delta(\bar{x}-f)}{(1-\delta)(f-\underline{x})}\right]}{\alpha[\bar{x}-\underline{x}]}>0 \\
\frac{\partial R^{*}}{\partial f} & =\frac{N}{\alpha(\bar{x}-\underline{x})}\left[\frac{-1}{(\bar{x}-f)}-\frac{1}{(f-\underline{x})}\right]<0
\end{aligned}
$$

\section{Appendix B: a numerical illustration}

The values of the variables (table 1) are adapted from Angelsen (1995, 1999). They correspond as far as possible to a household survey done in the Seberida district, Riau, Sumatra. For the variables not corresponding to the survey (i.e $\delta, \bar{x}, \underline{x}$, f and $\alpha$ ), we use values corresponding to the basic conditions of the model $((3),(2))$. 
Table 1: Parameter values of the numerical simulation

\begin{tabular}{|c|c|c|c|}
\hline Variable & Symbol & Initial value & Adapted value \\
\hline Total land area & $\mathrm{H}$ & 1932 & 1 \\
Number of households & $\mathrm{N}$ & 82 & 0.042 \\
Expected output in agriculture & $E(x)$ & 500 & 0.26 \\
Low level of output & $\underline{x}$ & n.a & 0.15 \\
High level of output & $\bar{x}$ & n.a & 0.37 \\
Forest products intensity & $\mathrm{f}$ & n.a & 0.22 \\
Probability of $\bar{x}$ & $\delta$ & n.a & 0.5 \\
Absolute Risk Aversion coefficient & $\alpha$ & n.a & 0.5 \\
\hline
\end{tabular}

n.a: not available

Source: Angelsen (1995, 1999)

Table 2: Results of the numerical simulation

\begin{tabular}{|c|c|c|}
\hline & Change in parameters & Diversification \\
\hline Initial situation & Cf Table 2 & 0.29 \\
\hline Risk reduction & $\bar{x}=0.36 ; \underline{x}=0.16$ & 0.36 \\
\hline Forest profitability & $f=0.2$ & 0.47 \\
& $f=0.24$ & 0.14 \\
\hline Risk aversion & $\alpha=0.3$ & 0.48 \\
& $\alpha=0.7$ & 0.21 \\
\hline
\end{tabular}




\section{Appendix C: $L_{c}$ as a fixed point}

The total amount of labor allocated to the CPR in the non-poverty-trap case is a fixed point. First, we need to prove that $U\left(L_{c}\right)+L_{c}^{M}\left(L_{c}\right)$ is decreasing in $L_{c}$.

Note that $U\left(L_{c}\right)$ is decreasing in $L_{c}$. Indeed the number of unskilled people is defined as: $E\left(x_{U}\right) \leq Y\left(L_{c}\right) / L_{c}$, which is decreasing in $L_{c}$ by assumption.

Therefore, if $L_{c}$ increases, some households pass from the unskilled class to the middle class. Those households reduce the amount of labor allocated to the CPR. Indeed, the unskilled households allocate all their labor to the CPR, while middle-class households allocate only a share of it.

Overall, an increase of $L_{c}$ induces a reduction in labor allocated by the unskilled class, which over-compensate the raise in labor allocated by the middle-class households. It follows that the total amount of labor allocated to the CPR decreases.

Second, $U\left(L_{c}\right)+L_{c}^{M}\left(L_{c}\right)$ is positive, as the amount of labor allocated by insurance-seeking households is necessarily positive. It follows that $L_{c}=U\left(L_{c}\right)+L_{c}^{M}\left(L_{c}\right)$ is a fixed point.

\section{References}

Agarwal, B. (1991). Social security and the family: coping with seasonnality and calamity in rural India, pages 171-244. Social Security in Developing Countries, Ahmad, E.J. and Dreze, J. and Hills, J. and Sen, A. (eds.), Clarendon Press, Oxford.

Aldermann, H. and Paxson, C. (1994). Do the poor insure? A synthesis of the litterature on risk and consumption in developing countries, volume 4. Economics in a changing world, London, mcmillan edition.

Angelsen, A. (1995). Shifting cultivation and deforestation: A study from indonesia. World Development, 23(10).

Angelsen, A. (1999). Agricultural expansion and deforestation: Modelling the impact of population, market forces and property rights. Journal of Development Economics, 58:185218. 
Angelsen, A., Sunderlin, W., Ahmad Dermawan, D., and Rianto, E. (2001). Economic crisis, small farmer well-being, and forest cover change in indonesia. World Development, $29(5)$.

Angelsen, A. and Wunder, S. (2002). Exploring the forest-poverty link. CIFOR Occasional Paper n40.

Azariadis, C. and Stachurski, J. (2006). Poverty traps, pages 295-384. Handbook Of Economic Growth, Aghion, P. and Durlauf, S. (eds.), Elsevier.

Baland, J. and Francois, P. (2005). Commons as insurance and the welfare impact of privatization. Journal of Public Economics, 89(2-3):211-231.

Barbier, E. (2000). Links between economic liberalization and rural resource degradation in the developing countries. Agricultural Economics, 23:299-310.

Bluffstone, R. (1995). The effect of labor market performance on deforestation in developping countries under open access: An example from rural nepal. Journal of Environmental Economics and Management, 29:42-63.

Bromley, D. and Chavas, J. (1989). On risk, transactions and economic development in the semiarid tropics. Economic Development and Cultural Change, pages 719-736.

Byron, N. and Arnold, M. (1997). What future for the people of the tropical forests? CIFOR Working Paper n19.

Das Gupta, M. (1987). Informal security mechanisms and population retention in rural india. Economic Development and Cultural Change, 36(1):101-120.

Das Gupta, M. and Maler, K. (1993). Handbook of development economics, volume 3, chapter Poverty and the Environmental Resource Base. University of Cambridge.

Dercon, S. (2002). Income risk, coping strategies and safety nets. The World Bank Research Observer, 17(2):141-166.

FAO (1992). Forest resources assessment, tropical countries. Technical report, FAO, Rome; FAO. Forestry Paper n112. 
Jodha, N. (1986). Common property resources and rural poor in dry regions of india. Economic and Political Weekly, 21(27):1169-1182.

Kaimowitz, D. and Angelsen, A. (1998). Economic models of tropical deforestation: a review. CIFOR, www.cgiar.org/cifor.

Kaimowitz, D. and Angelsen, A. (1999). Rethinking the causes of deforestation: Lessons from economic models. The World Bank Research Observer, 14(1).

Kumar, S. (2002). Does participation in common pool resource management help the poor? a social cost-benefit analysis of joint forest management in jharkland, india. World Development, 30(5):763-782.

Lopez, R. (1986). Structural models of the farm household that allow for interdependent utility and profit-maximisation decisions, chapter 11. Johns Hopkins University Press, Baltimore, MD.

Lopez, R. (1998). Agricultural intensification, common property resources and the farmhousehold. Environmental and Resource Economics, 11(3-4).

Myer, N. (1992). Tropical forests; the policy challenge. Environmentalist, 12(1).

Neumann, R. and Hirsch, E. (2000). Commercialisation of non-timber forest products: a review. Technical report, CIFOR, Bogor, Indonesia and FAO, Rome.

Parks, P., Barbie, E., and Burgess, J. (1998). The economics of forest land use in temperate and tropical areas. Environmental and Resource Economics, 11(3-4).

Pattanayak, S. and Sills, E. (2001). Do tropical forests provide natural insurance? the microeconommics of non-timber forest product collection in the brazilian amazon. Land Economics, 77(4):595-612.

Reddy, S. and Chakravaty, S. (1999). Forest dependence and income distribution in a subsistence economy. World Development, 27(7):1141-1149.

Repetto, R. and Gillis, M., editors (1988). Public Policies and the Misuse of Forest Resources. Cambridge University Press. 
Ros-Tonen, M. and Wiersum, F. (2003). The importance of non-timber forest products for forest-based rural livelihoods: an evolving research agenda. AGIDS.

Shiferaw, B. and Holden, S. (2000). Policy instruments for sustainable land management: The case of highland smallholders in ethiopia. Agricultural Economics, 22:217-232.

Shiferaw, B. and Holden, S. (2004). Land degradation, drought and food security in a lessfavoured area in the ethiopian highlands: a bio-economic model with market imperfections. Agricultural Economics, 30:31-49.

Singh, I., Squire, L., and Strauss, J., editors (1986). Agricultural household models: Extensions, Applications and Policy. Johns Hopkins University Press, Baltimore, MD.

Sydorovych, O. (2001). Economics of the forest land use in developing countries a brief literature survey. North Carolina State University.

Taylor, E. and Adelman, I. (2003). Agricultural household models: Genesis, evolution, and extensions. Review of Economics of the Households, 1(1).

Torkamani, J. and Haji-Rahimi, M. (2001). Evaluation of farmer's risk attitudes using alternatives utility functional forms. Journal of Agricultural Science and Techonology, 3:243-248.

UNEP (2003). Geo 2003. chapitre 2: Les forets. Technical report, UNEP, www.unep.org.

Wollenberg, E. and Ingles, A. (1998). Incomes from the forest. methods for the development and conservation of forest products for local communities. Technical report, CIFOR, Bogor, Indonesia.

WorldBank (2001). A revised forest strategy for the world bank group. Technical report, World Bank, Washington D.C.

Wunder, S. (2001a). Poverty alleviation and tropical forests: What scope for synergies? World Development, 29(11):1817-1833.

Wunder, S. (2001b). Poverty alleviation and tropical forests. what scope for synergies? World Development, 29(11). 